\title{
APRESENTAÇÃO
}

\section{Ensino de História e Consciência Histórica} History Teaching and Historical Consciousness

\author{
Luís Alberto Marques Alves* \\ Marcelo de Mello Rangel ${ }^{* *}$ \\ Tatyana de Amaral Maia ${ }^{\star * *}$
}

Este Dossiê busca refletir sobre a contribuição e a influência da obra de Jörn Rüsen para a Teoria e a Didática da História no quadro de requalificação do Ensino de História como campo de pesquisa no mundo ibero-americano. A partir dos anos 1970 e, principalmente, ao longo das décadas de 1980 e 1990, emergem, no campo da Didática da História, novas perspectivas teóricas profundamente influentes, propondo uma reflexão sobre a função da História (disciplina e ciência) na vida cotidiana. Essa dimensão prática da História consistiria em compreender e atuar diretamente sobre a consciência histórica dos alunos, leitores e indivíduos em geral.

Para Jörn Rüsen, a consciência histórica é uma determinação antropológica que possibilitaria a ordenação temporal do vivido, dando às experiências um sentido coletivo. Trata-se de uma operação necessária à percepção do

\footnotetext{
* Professor associado com agregação do Departamento de História e Estudos Políticos e Internacionais da Faculdade de Letras da Universidade do Porto. Investigador do Centro de Investigação Transdisciplinar Cultura, Espaço e Memória (CITCEM). Porto, Portugal. laalves@ letras.up.pt

** Doutor em História. Professor do Departamento de História e do Programa de Pós-Graduação em História da Universidade Federal de Ouro Preto (Ufop). Ouro Preto, MG, Brasil. mmellorangel@ yahoo.com.br

*** Doutora em História. Professora adjunta do Departamento de História e do Programa de Pós-Graduação em História da Pontifícia Universidade Católica do Rio Grande do Sul (PUC-RS). Porto Alegre, RS, Brasil. tatyana.maia@pucrs.br
} 
indivíduo como sujeito histórico, ou seja, imerso num determinando tempo e espaço, inserindo-o no coletivo. Por sua vez, o humanismo histórico que constitui referência conceitual dos seus textos permite também associar essa consciência à tolerância e ao que podemos chamar de uma cidadania comprometida, constituindo, assim, um espaço importante para a intensificação de certa orientação ético-política no interior do ensino de história, da teoria da história, da história da historiografia e da disciplina em geral no interior do mundo contemporâneo.

Os trabalhos aqui reunidos refletem a multiplicidade de apropriações e possibilidades de análise da consciência histórica e do papel decisivo do Ensino de História na formação do pensamento histórico. O conceito de consciência histórica possui múltiplas definições entre os teóricos da epistemologia da História e da Didática. A partir da apropriação do conceito de consciência histórica, historiadores e professores europeus e brasileiros têm se dedicado a avaliar o papel do ensino da História e de sua aprendizagem, dentro e fora da sala de aula, incorporando às suas análises a dimensão da formação do pensamento histórico na construção de representações do mundo social. Para nós, organizadores, a possibilidade de reunir os trabalhos desses pesquisadores no âmbito da Educação Histórica e da epistemologia da Didática da História fundamentada no conceito da consciência histórica demonstra a maturidade desse campo de pesquisa em países como Brasil e Portugal, assim como sua pluralidade saudável.

A significativa influência do historiador alemão no Brasil e na Europa justifica a importância de um Dossiê sobre as possibilidades trazidas por suas proposições teóricas para os campos do ensino de História, da teoria da história e da história da historiografia. O conjunto de artigos também propõe fazer uma leitura contextualizada do pensamento de Rüsen.

A composição de autores para este Dossiê, com pesquisadores brasileiros e portugueses, demonstra a importância da realização de pesquisas e diálogos transnacionais, fundamentais ao processo de internacionalização do conhecimento a partir da troca de experiências. No caso do Brasil, pesquisadores de várias regiões do país contribuíram com suas pesquisas, demonstrando as especificidades dos aspectos locais e do contexto escolar e historiográfico nos quais ocorre a aprendizagem histórica. Os autores brasileiros que contribuíram com 
artigos para este Dossiê foram: a professora Cláudia Cristina da Silva Fontineles (UFPI) com um artigo dedicado ao uso de artefatos culturais, especificamente a literatura e a música, no ensino de História; a professora Maria Auxiliadora Schmidt (UFPR) com um artigo sobre jovens estudantes e sua participação nos movimentos recentes, à luz da consciência histórica; e o professor Rafael Saddi Teixeira (UFG) que propõe uma reflexão sobre as potencialidades e limites da teoria de Rüsen, em especial, da autonomia do indivíduo frente às instituições e normatizações no campo do ensino. Os autores portugueses também pertencem a diferentes instituições e atuam em vários níveis do Ensino. As professoras Cláudia Sofia Pinto Ribeiro (Universidade do Porto) e Cláudia Nóbrega destacam a importância das sensibilidades e emoções no Ensino de História, em especial na progressão da consciência histórica; a professora Helena Pinto, com doutorado pela Universidade do Minho, escreve sobre a importância da educação patrimonial como tema transversal no Ensino de História, no âmbito da Educação Histórica. O professor Luís Alberto Marques Alves (Universidade do Porto) propõe uma reflexão epistemológica sobre os caminhos da Didática, destacando o papel interdisciplinar do processo de renovação do campo e a importância da consciência histórica no exercício da cidadania. Por fim, a professora Marília Gago (Instituto Superior de Ciências Educativas, Odivelas, Lisboa) também se concentra no debate epistemológico, observando a centralidade da narrativa de professores e alunos para a perspectiva da Educação Histórica e como elemento estruturante da consciência histórica.

A professora Marília Gago também foi a responsável pela entrevista com Jörn Rüsen, publicada em inglês e português. Aliás, a publicação da entrevista em português só foi possível graças à tradução realizada pelo Centro de Investigação Transdisciplinar Cultura, Espaço e Memória, da Faculdade de Letras da Universidade do Porto, que acolhe vários dos pesquisadores que contribuíram para este Dossiê, de modo que fica aqui registrado o nosso agradecimento pelo apoio.

A seção E-storia conta com o artigo dos pesquisadores portugueses Helena Vieira e Cristiano Ferreira sobre experiências com aplicativos móveis no ensino de História, entendendo-os como instrumentos capazes de entusiasmar os alunos para um aprendizado participativo e integrado às novas tecnologias. 
Por fim, três resenhas compõem este Dossiê, trazendo leituras críticas sobre livros recentes dedicados ao Ensino de História no Brasil e em Portugal.

O Dossiê também reflete uma parceria entre os organizadores, iniciada em 2012, cujo desdobramento tem sido o diálogo contínuo por meio da organização de eventos e publicações coletivas.

Agradecemos à Anpuh, a todos os colaboradores da Revista História Hoje e, em especial, à atual editora da revista, professora Cristiani Bereta da Silva. A organização de um Dossiê é sempre um desafio. Sem o apoio de todos, autores, editores e equipe, sua publicação não seria possível. Esperamos que os trabalhos aqui reunidos possam contribuir com o diálogo e atender às expectativas do público leitor. 